IZA DP No. 9343

Cultural and Ethnic Differences in the Transitions from Work to "Retirement" of Rural Elders in China's Minority Regions

Rachel Connelly

Margaret Maurer-Fazio

September 2015 


\title{
Cultural and Ethnic Differences in the Transitions from Work to "Retirement" of Rural Elders in China's Minority Regions
}

\author{
Rachel Connelly
}

Bowdoin College and IZA

Margaret Maurer-Fazio
Bates College and IZA

\author{
Discussion Paper No. 9343 \\ September 2015
}

\author{
IZA \\ P.O. Box 7240 \\ 53072 Bonn \\ Germany \\ Phone: +49-228-3894-0 \\ Fax: +49-228-3894-180 \\ E-mail: iza@iza.org
}

\begin{abstract}
Any opinions expressed here are those of the author(s) and not those of IZA. Research published in this series may include views on policy, but the institute itself takes no institutional policy positions. The IZA research network is committed to the IZA Guiding Principles of Research Integrity.

The Institute for the Study of Labor (IZA) in Bonn is a local and virtual international research center and a place of communication between science, politics and business. IZA is an independent nonprofit organization supported by Deutsche Post Foundation. The center is associated with the University of Bonn and offers a stimulating research environment through its international network, workshops and conferences, data service, project support, research visits and doctoral program. IZA engages in (i) original and internationally competitive research in all fields of labor economics, (ii) development of policy concepts, and (iii) dissemination of research results and concepts to the interested public.
\end{abstract}

IZA Discussion Papers often represent preliminary work and are circulated to encourage discussion. Citation of such a paper should account for its provisional character. A revised version may be available directly from the author. 
IZA Discussion Paper No. 9343

September 2015

\section{ABSTRACT}

\section{Cultural and Ethnic Differences in the Transitions from Work to "Retirement" of Rural Elders in China's Minority Regions}

This paper considers the work to "retirement" transitions of the rural elders in China who reside in seven regions with substantial minority populations. The data employed, those of the China Household Ethnicity Survey, are ideal for examining the effect of cultural differences on this key lifecycle event, the reduction of market-oriented work with age. Membership in particular ethnic minority groups is used to proxy the potential differences in the culture of aging and caregiving. We find that beyond education, the strongest predictors of labor force participation for China's rural elders are age, disability, widowhood, and ethnic minority status. The effects of ethnic minority group status on labor force participation are robust and the differences in participation among ethnic groups are sometimes large. It is thus misleading, in the analysis of the labor force participation of China's rural elders, to simply dichotomize ethnic minority and majority (Han) group membership. Further careful research is needed to help understand the differences in perceptions of aging among China's rural ethnic minority groups.

JEL Classification: J14, J15, J16, J26, D13, O53

Keywords: ethnicity, retirement, labor force participation, elders, aging, China Household Ethnicity Survey

Corresponding author:

Margaret Maurer-Fazio

Bates College

276 Pettengill Hall

4 Andrews Road

Lewiston, Maine 04240

USA

E-mail: mmaurer@bates.edu 
Cultural and Ethnic Differences in the Transitions from Work to "Retirement” of Western China's Rural Elders

Rachel Connelly and Margaret Maurer-Fazio

The aging of the Chinese population and the massive migration of rural residents to urban areas are the two most important demographic phenomena of late $20^{\text {th }}$ century, early $21^{\text {st }}$ century China. By 2000, China had joined the ranks of aging societies as defined by Cai et al, (2012, p.12) as those with at least 10 percent of their population aged 60 and above and 7.5 percent aged 65 and above. By 2010, 14 percent of China's population was 60 years of age or older. The share of this age group is expected to increase to 20 percent by 2020 and 27 percent by 2030 (Wang, 2012). The labor migration of young workers from rural to urban China, which began in the mid-1980s and grew in earnest in the 1990s with the increased demand for labor in the growing export and service economies and easing of hukou regulations, has since expanded dramatically in all dimensions. The average age of migrants is increasing, the length of time they stay in urban areas is lengthening, their sex ratio is shifting to more closely reflect their sending communities, and the list of their sending places/places of origin is growing rapidly. Official government statistics put the number of rural migrants employed in cities at 79 million in 2000 and 163 million in 2012 (NBS 2012a cited in World Bank SRs4-7, 2014). In 2013, the floating population reached 245 million and rural migrant workers constituted 44 percent of total urban employment (World Bank, SRs4-7, p.265). The aging of the rural population, coupled with the massive out-migration of young people from the countryside, raises concerns about who will replace and refresh the rural labor force and who will care for the elders left behind in the countryside.

The notion of retirement is practically non-existent in many developing countries-especially in their rural areas. When Giles, Wang and Cai (2011) compare the labor supply and retirement behavior of Chinese elders to that of elders in Indonesia, Korea, the United States, and the United Kingdom, they find that in Korea, Indonesia, and China, rural elders are less likely to retire than their urban counterparts. In addition, Connelly, Maurer-Fazio and Zhang (2014), based on data from the 1982 and 2000 Chinese population censuses, find that the labor force participation rates of China's rural elders increased over time. They report that the participation rate of rural men, age 50 to 74, increased from 71 percent to 79 percent over this 18 year period, while rural women's participation increased, remarkably, from 28 percent to 59 percent. Previous research suggests that the increase in the labor force participation of China's rural elders stems from a combination of increased market incentives, changing conceptions of work that are increasingly market oriented, better health, increased economic uncertainty, and the migration of younger workers to urban areas.

In this chapter, we examine the role that culture, in conjunction with more standard economic and demographic characteristics, plays in labor force participation decisions of China's rural elders. We proxy cultural differences here mainly by means of specific ethnic minority 
memberships, but also by means of the differences in the effects of age and widowhood across gender lines. Based on profiles of labor force participation rates by age, it is clear that the age range of 50 to 74 is one of particularly heightened decision-making with regard to elders' labor force participation. It is thus an exceptionally good lens with which to view the effects of culture on such decisions. At younger ages, almost all rural residents are "in the labor force," that is, engaged in labor for the purpose of earning income--either directly or in the production of commodities that will be offered for sale. By age 75 few remain in the labor force. By focusing on rural residents between the ages of 50 and 74, that is, a group of relatively young elders, we capture the segment of the population actively making decisions about continuing to work or to retreat from the labor force.

To suggest that culture plays an important role in such decisions about transitions from labor force participation seems reasonable. Sociologists and anthropologists have long focused on culture as a determinant of human behavior and have noted a strong inclination of individuals to conform to norms, to behave in ways similar to their neighbors. Economists have more recently begun to pay close attention to the role of culture in explaining differing responses of individuals to similar economic incentives. ${ }^{1}$ The decision about when to reduce one's work may depend on expectations that are formed through childhood, education, and socialization about elder care, living arrangements, and filial piety as well as by observations of local norms, of what one's neighbors are doing.

Previous research has found differences in labor force participation by ethnicity in China. (Maurer-Fazio, Hughes and Zhang, 2007, 2010; Connelly, Maurer-Fazio and Zhang, 2014) Each of these papers is based on the 2000 Chinese Population Census, which, unfortunately, lacks information on earnings, and contains very little on wealth and health. Until now, though, census data was the only source of data with enough observations to separately analyze China's multiple ethnic minority groups. This changed with the collection of the 2011 Chinese Household Ethnic Survey (CHES), which we employ here. We focus on rural elders and thus restrict our use of the data to its rural sub-sample. Nine ethnic minority groups have large enough sample sizes in the CHES for separate designations and inclusion in our analysis: Mongolian, Hui, Tibetan, Uygur, Miao, Zhuang, Dong, Yao and Tujia. Members of other ethnic minorities are also included in our analysis but aggregated into a category labeled, “other.” All 10 groups are compared to the Han, who constitute the majority, even in this minority-rich rural sample.

In the analysis that follows, we find that ethnic group membership plays a significant role in the labor force participation decisions of China's rural elders. Large differences in labor force participation by ethnicity exist in our simple descriptive analysis. Most of these differences

\footnotetext{
${ }^{1}$ See Burda, Hamermesh and Weil (2013) for a model of the cultural components of gender work differences. Blau et al (2013) find substantial transmission of gender norms across generations of immigrants to the U.S. that affect women's decisions on fertility and labor supply.
} 
remain even after we control for respondents' economic and demographic characteristics. For men, the marginal effect of ethnicity on labor force participation is statistically significant for seven of our ten specific ethnic groups: Mongolian, Uygur, Miao, Zhuang, Dong, Yao, and Tujia. Each of these groups has significantly higher rates of labor force participation than the Han. In addition, there are large differences in participation rates among the groups with Tujia men at a high of 94 percent and the Dong and Uygur men at only 71 percent. For women, eight of the ethnic groups in our data have rates that are different from the Han. The Hui and Uygur female elders have lower rates of participation, while the Mongolian, Miao, Zhuang, Dong, Yao and Tujia have higher rates. Again there is a substantial range of participation rates among the various ethnic minority women: the Yao, Tujia and Mongolian female elders have rates above 60 percent, while the Dong and Zhuang have rates closer to 50 percent. Beyond these direct effects of ethnic group membership on labor force participation, we find that the interaction of ethnic group membership and age also significantly affects labor force participation.

The role of culture or norms can also be seen in differences in the effect of age on labor force participation for men and women. Women are more likely to report, at younger ages than men, “doing housework" rather than "having a job.” Becoming a widow has a large negative effect on both labor force participation and hours worked for both men and women, but the effect is larger for women. These gender differences are difficult to explain except to say that the roles that rural men and women play in the economy differ socially and culturally.

In the largely agricultural setting in which most of the rural CHES respondents live, elders rarely ever think of themselves, or define themselves, as retired. When asked about their employment status, the most common response offered as an alternative to working was not retirement, but rather, keeping house. When we consider alternative measures of work and/or employment status such as the number of hours worked, or reports of no hours worked either on or off the farm over the previous year, our main results still hold. Elders' reported hours of work decline with age and differ in significant ways by ethnicity.

The rest of the chapter proceeds as follows: Section 2 reviews the previous literature on Chinese elders' labor force participation and employment. Section 3 outlines the socioeconomic, health and cultural factors expected to affect the employment decisions of rural elders. Sections 4 and 5 examine the patterns of employment and hours worked of elders in the CHES data. Section 6 offers some conclusions.

\section{II: Literature Review of Chinese Elders’ Labor Force Participation}

There is a lively, broad-based academic literature on the labor force participation and retirement decisions of adults between the ages of 50 and 74 . This age range represents the margin where adults make transitions from being predominantly employed to predominantly out of the labor force. In most developed countries, the labor force participation of adults in this age group fell substantially over most of the $20^{\text {th }}$ century, although there has been a modest increase 
in their participation over the last ten years. (Gendell, 2008) A similar pattern emerged in urban China (Giles, Wang, and Cai, 2011; Connelly, Maurer-Fazio, and Zhang, 2014). We note however, that worldwide, labor participation decisions of rural elders tend to differ from those of their urban counterparts. These differences stem from a combination of institutional factors including a lack of rural pensions and governmental social security and old age support, the relative ease of moving in and out of agricultural employment, and the income and wealth gaps between urban and rural areas.

Recent analyses of the specific determinants of China's rural elders' labor force participation decisions have considered the importance of wealth, pension availability, health, coresidence with adult children, and migration of adult children, as well as the effects of more standard socio-economic variables such as education, age and gender (Pang, deBrauw, and Rozelle, 2004; Giles, Wang, and Cai, 2011; Connelly, Maurer-Fazio, and Zhang, 2014). ${ }^{2}$ Both Pang, deBrauw, and Rozelle (2004) and Giles, Wang, and Cai (2011) find negative effects of pension availability on rural worker's labor force participation. For women, it is their spouse's pension availability that matters, while for men it is their own pension availability that affects their decisions (Giles, Wang, and Cai, 2011). Pang, deBrauw, and Rozelle (2004) find that wealth has no effect on formal labor force participation, while Giles, Wang, and Cai (2011) find some evidence that rural women who live in houses of greater value are less likely to be employed.

Connelly, Maurer-Fazio and Zhang (2014) focus on the effect of elders' coresidence with their adult children and grandchildren on the probability of their labor force participation. They find small negative effects of coresidence with adult children on both male and female elders' labor force participation when coresidence is assumed to be independent of other factors that might influence labor force participation. They find a much larger (in absolute value) negative effect of coresidence on labor force participation when they explicitly model the interdependence of the decisions to live with one's children and to work. Pang, deBrauw and Rozelle (2004) also include (exogenous) coresidence with adult children and find that it has a significant negative effect on elders' labor force participation.

Age and gender are important predictors of labor force participation and/or employment in each of the three analyses discussed above. Labor force participation rates decline with age and are lower for women than men. The decline in labor force participation with age may be, in large part, health related, but we hypothesize that there is also a cultural dimension to this trend.

\footnotetext{
${ }^{2}$ Giles, Wang and Cai (2011) analyze the rural population over age 45, Pang, deBrauw and Rozelle (2004) analyze the rural population over age 50 and Connelly, Maurer-Fazio, and Zhang (2014) analyze the rural population age 50 to 74. Pang, deBrauw and Rozelle (2004) control for gender differences with a simple dummy variable, while Giles, Wang and Cai (2011) and Connelly, Maurer-Fazio, and Zhang (2014) estimate their multivariate models separately for men and women. The data sources are: a specially collected survey of 60 villages in 6 provinces in 2000 (Pang, deBrauw and Rozelle); 2008 Chinese Health and Retirement Longitudinal Study (CHARLS) pilot survey from Gansu and Zhejiang provinces (Giles, Wang and Cai); and the 2000 Chinese Population Census, .095\% sample compared to the 1982 Chinese Population Census 1\% sample (Connelly, Maurer-Fazio, and Zhang).
} 
Both Pang, deBrauw and Rozelle (2004) and Giles, Wang and Cai (2011) control for health status and yet still find significant negative effects of age on participation. Similarly, the differences between men and women's participation are unlikely to be exclusively health related and are likely to be partially determined by cultural beliefs about gender roles. In the analysis that follows, we find, unsurprisingly, that women do more hours of housework per day than men. We also find that when hours of market work and housework are aggregated, women work more hours per day than men at every age, regardless of their labor force status even though women's labor force participation rates are lower than men's at every age.

Marital status is another important determinant of labor force participation in each of the three papers discussed above. Elders who are widowed are less likely to be in the labor market than those whose spouses are living. Connelly, Maurer-Fazio, and Zhang (2014) find that widowhood is a strong predictor of elders' coresidence with their adult children. And after controlling for the interdependence of coresidence with adult children and labor force participation, they find an additional effect of marital status. That is, married male and female elders are more likely to be in the labor market than their widowed and non-married counterparts. Similarly, Pang, deBrauw and Rozelle (2004) find that married elders are more likely to continue to do commercial farm work.

Beyond their focus on coresidence with adult children and grandchildren, Connelly, Maurer-Fazio and Zhang (2014) also find that two variables, both thought to capture some aspects of local gender norms, matter. The prefectural sex ratio of very young children and the prefectural gender gap in adult illiteracy rates (men's minus women's) each increase women's labor force participation. Thus, older women who live in areas with greater pro-male bias, by either measure, are more likely to be employed between the ages of 50 and 74 than those who live in areas with less pro-male bias. However, these two variables affect older men's labor force participation differently. The prefectural sex ratio of young children has no effect on men's labor force participation, while there is a negative effect on their participation of the gender gap in adult illiteracy. The effects of these two variables provide limited evidence that cultural differences (at least in terms of women's bargaining power and the strength of son preference) affect labor force participation rates, even after controlling for individual demographic characteristics. In this chapter we further explore the role that cultural differences play in the labor force participation/hours worked decisions made by China's rural elders. We do so by adding detailed information about the rural elders' ethnic minority group status.

It would be ideal to have specific hypotheses about why the elders of particular ethnic groups in China might be expected to have higher or lower labor force participation rates/hours work than those of other minorities or the Han, but we have unearthed no prior research that could serve as a foundation for forming such hypotheses. There is certainly a substantial body of scholarship focused on ethnic minority groups in China. The emphasis, however, is seldom 
comparative and does not focus on aging. ${ }^{3}$ Thus, our empirical work on the effect of ethnic minority status on elders' employment and hours worked must be considered exploratory. That ethnic differences emerge after controlling for the standard demographic and socioeconomic variables usually related to labor force participation decisions is thought provoking. We hope this finding will motivate a new generation of social scientists to return to the topic of comparative gerontology, which we believe will prove important with the rapid aging of the China's population.

\section{III: Factors Affecting the Labor Force Transitions of Contemporary Rural Elders}

Given the findings of the research discussed above, we expect that elders' work decisions are made in the context of their interconnectedness with adult children. At least four aspects of elders' lives should be considered. The first is their living arrangements. Related to living arrangements is the demand for elders' labor, particularly in agriculture. The second is the level of wealth, income, and poverty experienced by elders and how these factors affect elders' labor force participation and transitions to retirement. A third important consideration is how elders' health affects their potential employment, and the fourth is cultural constructs and norms about aging, proxied here by ethnic minority group membership and the cultural construct of gender and the interactions of these two factors.

\section{III.A: Living Arrangements and the Demand for Elders' Labor}

In a Western context, living with one's adult children is most often connected with elders' frailty or particular incapacities. This is certainly not the case in rural China. Using data from the 2000 population census, Connelly, Iannotti, Maurer-Fazio, and Zhang (2015) find that in 2000, rural elders who resided in the same counties that were surveyed in CHES had high rates of coresidency with their adult children. Then using the CHES data, they report that these coresidency rates remained high in 2011. Although disability is positively related to coresidence, most elders live with their children long before they become disabled. MaurerFazio et al (2011) find that in urban China, coresidence with one's parents increases prime-aged women's labor force participation, providing circumstantial evidence that elders are helping with childcare and other housework. Connelly, Maurer-Fazio, and Zhang (2014) directly examine the effect of coresidence on the labor force participation of elders aged 50 to 74 using the 2000 Census and find that coresidence exerts a negative effect on labor force participation for rural, but not urban, elders.

\footnotetext{
${ }^{3}$ The focus of much of the anthropological work on China's ethnic minorities has been on the State's role in the creation of ethnic identity in China. One prolific anthropologist who works on Chinese ethnic minority culture in Southwestern China, Stevan Harrell, edited a 1981 volume titled Other Ways of Growing Old: Anthropological Perspectives. However, an extensive bibliographic search has failed to find any newer pieces focused on aging and China's ethnic minorities.
} 
Although the coresidence of China's rural elders with their adult children may not be primarily "caused" by incapacity, it is still important to think of, and model, their employment and coresidency decisions as jointly determined. Living with one's children reduces the transactions cost of many types of time transfers. Adult children are available "to do the heavy lifting," while the elders are available to hold the baby and feed the chickens. In addition, while coresidency provides more bodies to do the work, it also creates more tasks to do. How these tasks get divided between "housework" and "employment" in the minds of the residents of these primarily agricultural households is unclear a priori. However, previous findings lead us to predict that coresidency will lead to a decline in rural elders' labor force participation.

Widowhood is strongly associated with the coresidence of elders with their adult children in both rural and urban China (Connelly, Iannotti, Maurer-Fazio, and Zhang 2015; Connelly, Maurer-Fazio, and Zhang 2014). It also reduces labor force participation, even after controlling for coresidence. (Connelly, Maurer-Fazio, and Zhang 2014, Pang, deBrauw, and Rozelle 2004) Since other variables such as age are controlled for, the relationship between widowhood and labor force participation may reflect correlated health status. It may also reflect a cultural milestone: widowhood may function as the "on switch" for filial responsibility and signal a need to be cared for, regardless of actual health status. In the analysis that follows, given the availability of health information in the CHES data, we distinguish between these two hypotheses.

The demand for the elders' labor within the household is also likely to be affected by the labor decisions of their children, regardless of whether they live together. In the context of rural China, the two most important labor decisions facing the younger generation are the decisions about whether or not to migrate and whether or not to work off farm. Given that almost all rural families in the CHES sample are still involved in farming, we expect that the younger generation's decisions to migrate and to work off farm will each increase the work hours of the older generation. The effect is expected to differ by gender. Chang, Dong and MacPhail (2011) and $\mathrm{Mu}$ and van de Walle (2011) each show that migration increased the work hours of elderly women more than that of elderly men. On the other hand, Pang, deBrauw and Rozelle (2004) found that after controlling for coresidence and health status, the migration status of their children was not a significant determinant of the elders' labor force participation or their labor supply in farm work and/or off-farm work.

\section{III.B: Income, Wealth and Poverty}

Although standard economic models of labor supply are agnostic with respect to the effect of higher income on labor supply, they unambiguously predict that higher levels of wealth will reduce labor supply. The ambiguity of income's effect on labor supply stems from opposing consequences of having more money to live on (the income effect) and having a higher opportunity cost of one's time (the substitution effect). However, most practitioners expect that elders' labor force participation will decline with income, given that elders are much closer than 
the young or middle-aged to the decision margin of whether to continue with employment/work. Researchers have employed a number of different variables in their attempts to capture these wealth and income effects. Pang, deBrauw and Rozelle (2004) include education, per-capita income, and the amount of land contracted to the household (the amount of land being farmed affects the demand for labor). Giles, Wang and Cai (2011) include education, average education of spouse and adult children, pension eligibility, spouse's pension eligibility, and housing wealth. Connelly, Maurer-Fazio, Zhang (2014) include education and provincial average per-capita income and GDP growth rates.

\section{III.C: Health}

In every society, labor supply declines with age as the aging process inevitably affects strength, balance, mobility, and energy levels. Even if rural Chinese "work until they drop," the intensity of work and the tasks engaged in change and become much less likely to be considered as labor force participation. Expectations about appropriate ages at which to work hard and at which to take it easy may also be determined, in part, along cultural lines. Labor market institutions such as pension and insurance also exert age effects on labor supply through their eligibility/entitlement criteria.

We expect, in addition to age, that individuals' health status will also affect their employment. Giles, Wang and Cai (2011) employ two levels of Activity of Daily Living (ADL) scores to control for health status: "with difficulty" and "unable." Pang, deBrauw and Rozelle (2004) include controls for individuals who report themselves "moderately ill" and "severely ill." In both of these studies, as expected, the variables used to control for poor health exert strong negative effects on the labor force participation China's rural elders.

\section{III.D: Ethnic Minority Difference}

Cultural and social norms affect how people view their set of life choices. People do not make individual decisions in a vacuum, but rather look around and see what other people in similar circumstances are doing. The issue of culture is particularly important when we consider elder care. There is no uniformity in the human approach to this matter. While some cultures value independence above collective destinies and are more likely to look for market solutions for care needs, others rely on extended households to provide care for the young and the old.

In China, particular ethnic minorities have maintained their own cultures over long periods of time. In some places, minority groups are geographically isolated from one another, which has facilitated separate cultures. In other places, different minority groups live in close proximity to one another. Connelly, Iannotti, Maurer-Fazio, and Zhang 2014 (2015) analyze rural elders' coresidency patterns and find that Tibetans, Uygurs, Zhuang, and Salar are each significantly more likely to live with their adult children than the Han. 
Maurer-Fazio, Hughes and Zhang (2010) find substantial differences in labor force participation by ethnicity among China's urban women aged 25 to 50 . Using the 2000 Chinese census, they compare six ethnic groups (and an aggregated "other ethnic" category) to the Han majority. They find that Hui, Korean, Mongolian and Uygur women have lower labor force participation rates than the Han, while the Zhuang have higher rates than the Han. The Manchu and "other" do not differ from the Han. For men in this age group, they report that labor force participation rates are so high, across the board, that no ethnic differences are observed.

Using the same 2000 population census data, Connelly, Maurer-Fazio and Zhang (2014) examine the labor force participation decisions of both urban and rural residents aged 50 to 74 , the age group in which most Chinese ultimately drop out of the labor force. They find that rural elders of Muslim minorities have higher labor force participation rates than others. Interestingly, the Muslim effect on labor force participation is negative for prime-age urban women (MaurerFazio et al, 2011), while it is positive for older rural women. The CHES data, which underlie the analysis of this chapter, allow us to look beyond the Muslim/Non-Muslim dichotomy of MaurerFazio et al (2011) and Connelly, Maurer-Fazio and Zhang (2014).

\section{IV: Data}

Our analysis is based on the rural subsample of the 2011 CHES data. The analysis of labor force participation and hours of work is focused on individuals between the ages of 50 and 74. The first stage of our two-stage estimation technique, that is, estimation of the coresidency of elders with their adult children, is based on a sample that includes all rural residents aged 50 and above. The calculation of prime-age, off-farm employment rates by county is based on individuals, aged 16 to 49 .

Labor force participation can be defined in several ways in the CHES data. For most of our analysis we use the respondents' answer to the question, "What was your work or study status during the last week in 2011?" If the respondent answered "working/ doing farm work/ engaged in family business activities" or "unemployed or waiting for a job assignment”, we classify the respondent as participating in the labor market. Using this definition of labor force participation, we find that 68 percent of these relatively young rural male elders and 45 percent of their female counterparts are in the labor force.

Among the other alternative answers to that question are "am retired" and "doing housework." The vast majority of these relatively young rural elders who are not in the labor force describe themselves as doing housework. Only 5 percent of the male and 1 percent of the female elders who are not in the labor force describe themselves as retired. This is strong evidence of the need to move away from the mono-directional "work then retire" model of labor force participation that is often used in studies of older adults.

[Table 1 here] 
Table 1 presents elders' labor force participation rates by five-year age cohorts based on the definition of participation described above. It reveals that labor force participation rates behave as we would expect; rates are much higher for younger cohorts than for older cohorts and higher for men than for women at each age category. In addition, the unemployment rate is higher for men than women. Although not shown in Table 1, women are much more likely than men to characterize themselves as doing housework. Seventy-four percent of the female elders, who are not in the labor force, characterize their work status as doing housework, compared to 57 percent of their male counterparts.

The CHES data allow us to define employment (rather than labor force participation) in two alternative ways. In one part of the survey, respondents were asked a set of time-use questions about their average hours per day spent in particular activities over the previous week. The first activity listed was "working." We could define individuals as employed if they had positive hours of work in the previous week. We call this definition "daily hours employed" in order to distinguish it from "work status employed." "Daily hours employed" is also used by Giles, Wang and Cai (2011) based on their use of the CHARLS data. Alternatively, we could define employment based on a set of questions related to annual work hours in 2011. The questions are similar to those used by Pang, deBrauw and Rozelle (2004), in which employment is separated into farm and off-farm categories. Time spent in farming is collected separately for busy and off seasons. Months worked are recorded separately from average weekly hours. Offfarm work time is also recorded separately for months worked and average weekly hours. We use these responses to calculate annual hours of work on and off farm. Employment can then be defined as having a positive number of annual hours of either farm or off-farm work in the previous year. We refer to this definition as "annual hours employed."

[Table 2 here]

These three alternative measures of employment status, available in the CHES data, are compared in Table 2. Based on Table 2, we conclude that use of the "daily hours employed" measure and/or the "annual hours employed" measure yield much higher employment rates at every age compared to the "work status employed" measure. Many of the respondents who report not being employed under the work status definition report a substantial numbers of annual or daily hours of work. The proportion employed, using all three measures, declines with age and is lower for women than men. Employment rates based on "daily hours employed" and "annual hours employed" are quite similar. The sample size is higher for the category of "annual hours employed" than for "daily hours employed" simply because there are fewer missing values in the responses to the underlying questions. Unfortunately, the daily time-use variables suffer from substantial missing values. ${ }^{4}$

\footnotetext{
${ }^{4}$ Only "hours worked" and "hours of housework" received responses from the majority of individuals. It may be that some enumerators did not record zero hours for the other possible responses, but rather treated the zero as a
} 
The definition of labor force participation used by Maurer-Fazio, Hughes, and Zhang (2010) and Connelly, Maurer-Fazio, and Zhang (2014) is based on yet another measure of labor supply. Both these studies use the Chinese Population Census and define individuals as being in the labor force if they supplied an occupation in response to the question "What is your current occupation?" or if they answer a work status question about why they are not employed with the response that they are looking for work. The levels of labor force participation of relatively young rural elders, based on the Census data, are close to the "work status" labor force participation measure presented in Table 1 above. According to the 2000 Census, the average labor force participation rate for all rural residents, age 50 to 74, was 79 percent for men and 60 percent for women. When we limit the census data to the same counties sampled in the CHES, the average labor force participation rates are 69 percent for male elders and 52 percent for female elders. ${ }^{5}$ These latter rates are quite close to the CHES data rates of 68 and 45 percent, respectively for male and female elders of the same age group.

Finally, the CHES data allow us to also analyze the number of hours worked and thus to consider the process of gradual retirement as discussed in Giles, Wang and Cai (2011) and Pang, deBrauw and Rozelle (2004). These measures of hours of work can also be compared to Chang, Dong and MacPhail (2011) who define elders as persons aged 51 and above. Table 3 reveals the number of daily hours reported as "work" and "housework" by both age cohort and labor force participation status (defined using the work status definition). The results in Table 3 show that work hours differ substantially by labor force participation. We also observe that hours of employment decline with age. Controlling for labor force participation, hours of employment are very similar for men and women.

[Table 3 here]

The fifth through eighth columns of Table 3 present hours of housework by labor force status and gender. Unlike work hours, housework hours do not differ by labor force participation status. Female elders perform about an hour a day more housework than their male counterparts. Adding housework hours and work hours together, to proxy for what Burda, Hamermesh, and Weil (2013) call "total work," we find that the elder women who report themselves as labor force participants, do the most work. ${ }^{6}$ But since women are less likely to be in the labor force than men, we use the last two columns of this table to compare "total work" independent of elders' labor force status. These data reveal that at the younger age cohorts (of these relatively young elders), women continue to do more hours of "total work" than men, but at the older ages "total work" hours decline for both men and women and become more similar across gender. Thus,

\footnotetext{
skip, while other enumerators did record zero hours. However, we do not feel comfortable assuming that all the missing time-use values are zero.

${ }^{5}$ We gratefully acknowledge Dandan Zhang's help in supplying these statistics based on the census data, limited to same counties included in the CHES data. .

${ }^{6}$ Note that this analysis excludes child care hours of which women do more than men. But as discussed in above, too few survey respondents answered the question about hours spent providing child care to include it here.
} 
hours of total work fall more rapidly for women than men, which leads ultimately to equality. This may be more a function of health than gender, but may also be related to the higher probability of being a widow than a widower.

\section{V: Labor Force Participation Patterns by Minority Status}

Having familiarized ourselves with the overall CHES data on labor force participation and employment, we next analyze ethnic minority differences in labor force participation. We do this, reassured that our measure of labor force participation based on work status behaves in ways we would expect in terms of age and gender. It is also the most similar measure of labor force participation to the census measures previously used to analyze labor participation by ethnicity and thus facilitates comparisons between these studies.

\section{[Table 4 here]}

Table 4 presents labor force participation rates by ethnic minority status separately for male and female elders. A quick look at Table 4 reveals that there are quite substantial differences in labor force participation rates by ethnicity for both men and women. Most of the ethnic minority groups (of those with samples large enough for analysis with the CHES data) have participation rates above those of the Han for both men and women. The Tibetans and the Hui are exceptions to this generalization. They have rates below the Han for both men and women, with the gaps larger for women than men. The Uygurs show yet another pattern with rates higher than the Han for men, but lower than the Han for women. There is substantial variation among the various groups. The Tujia have the highest rates, almost 20 percentage points higher than Miao men who themselves are 20 percentage points higher than the Hui men. Similarly female elders' rates vary from a high of 63 percent in the labor force for the Yao to a low of 15 percent for the Hui.

Of course, the differences in these raw labor force participation rates may be due to underlying economic and demographic differences between the groups. Following the work highlighted above by Chang, Dong, and MacPhail (2011), Connelly, Maurer-Fazio and Zhang (2014), Giles, Wang and Cai (2011), Mu and van de Walle (2011), and Pang, deBrauw and Rozelle (2004), we consider the effects of health, wealth, migration, and coresidence with adult children on the labor force participation rates of China's rural elders. The goal of this multivariate analysis is to determine whether the differences in participation attributed to ethnicity remain after controlling for these factors. ${ }^{7}$

\footnotetext{
${ }^{7}$ Giles, Wang and Cai (2011), Pang, deBrauw and Rozelle (2004) analyze employment rather than labor force participation. However, given the very low rates of unemployment among rural elders, there is little difference between employment and labor force participation. Chang, Dong, and MacPhail (2011) and Mu and van de Walle (2011) study hours worked. Table 3 implies that analysis of hours worked and labor force participation should yield similar results. We also analyze hours worked and discuss and compare the results throughout the remaining pages of this chapter.
} 
[Tables 5 and 6 here]

Tables 5 and 6 reveal, by ethnic minority status, summary statistics for the key variables included in the multivariate analysis that follows. The average levels of education, proportion of households with out-migrants, and rates of coresidency with adult children differ substantially by ethnic group. Average age, levels of disability, and proportion of prime-age adults engaged in off-farm employment in one's county of residence are quite similar across ethnic groups. Table 6 also provides information on the sample size available in the CHES by ethnic minority status. Close to half of the sample for each ethnic minority group is female.

[Figure 1a-1d here]

Tables 2 and 3 demonstrate that labor force participation declines with age. Figures 1a and $1 \mathrm{~b}$ provide the age trajectories for male elders. Figures $1 \mathrm{c}$ and $1 \mathrm{~d}$ show the age trajectories for female elders. These figures reveal that the patterns of labor force participation by age differ by ethnic minority group and gender. Figures $1 \mathrm{a}$ and $1 \mathrm{c}$ include the minority groups with participation rates generally above the Han. Even among these groups, there is substantial variation for men in the age ranges of 60 to 64 and 65 to 70 . For women, the variation in rates occurs earlier in the age range of 55 to 64 . In the multivariate model that follows, we allow for differences in the effect of age by ethnicity. Although this interaction complicates the model, it allows an important source of difference across minority group-- difference in how age is viewed with respect to labor force participation.

\section{VI: Multivariate Analysis of Labor Force Participation}

The full regression model results are presented in Appendix Table A-1. Here we discuss the highlights.

\section{VI.A: Living Arrangements and Demands for Elder's Agricultural Labor}

Variables included in the model to capture the multidimensional issues surrounding living arrangements include an indicator of whether an elder is living with one of his or her adult children and also the residual between the indicator of coresidence and the predicted probability of coresidency, ${ }^{8}$ an indicator of whether the elder is a widow or widower, and an indicator of whether the elder's household includes a migrant member who is currently away from the village. Two village-level variables are also included: the average off-farm labor force

\footnotetext{
${ }^{8}$ Including the residual follows the Two-Stage Residual Inclusion (2SRI) method of Terza, Basu, and Rathouz (2008) as a means of controlling for the potential endogeneity of the coresidency decision. The 2SRI method produces consistent estimates that are easy to interpret. The marginal effect of the coresidency indicator can be thought of as the exogenous effect of coresidency on labor force participation and the marginal effect of the residual can be thought of as the correlation between the unobserved factors leading to coresidency and labor force participation.
} 
participation of prime-age workers in the same village, and the number of out-migrants from the village (as reported by a village official).

We find that coresidency with adult children is independent of labor force participation for men, but has a large, statistically significant negative effect on women. The gender difference in the response to coresidency is quite robust to slight changes in the model specification. We speculate that these gendered differences in the effects of coresidency on elder men and women's labor force participation may occur because coresidency is itself often closely associated with the housework/child care responsibilities predominantly provided by women.

Widowhood has a negative effect on labor force participation of both men and women, reducing the probability of labor force participation by 16 percentage points for men and 10 percentage points for women. Since age, self-reported health, and coresidence are also controlled, it appears that widowhood itself brings with it an expectation that it is time to "stop working." We put the term "stop working" in quotes, since our analysis of hours worked above reveals that almost all elders, regardless of whether they think of themselves as still working, report hours of agricultural work and housework. In additional regression models not included here, we find that widowhood has no effect on the probability that elder men report positive annual hours off-farm or farm work, but is a significant negative predictor of farm work for women.

We are somewhat surprised that having an out-migrant listed in one's household register has no effect on the labor force participation male and female elders. This result differs from the results of Chang, Dong and MacPhail (2011) and Mu and van de Walle (2011). It may be the case that in many of these elder households, it is the grandchildren rather than the adult children who are the migrants. Perhaps grandchildren and elders are not close substitutes for one another in rural employment.

Neither of the two village-level variables, the number of out-migrants from the village and the share of the prime-age population employed off-farm have an effect on men's or women's labor force participation. However, the share of off-farm village employment does significantly increase the probability that male and female elders participate in off-farm employment (results not shown).

\section{VI.B: Income and Wealth Measures}

Education matters for both men and women. The higher the level of their education, the more likely it is that rural elders report that they are in the labor force. Low educational attainment consistently affects employment and labor force participation, regardless of the measures we employ. Not having attended primary school significantly reduces men's farm and off-farm employment as well as women's farm employment (results not shown). It also significantly reduces annual hours worked on and off farm for men and on farm for women (results not shown). The strong negative gradient of education is surprising, given that education 
is correlated with wealth and more wealth is usually shown to reduce labor supply. Of course, education also affects the opportunity cost of employment (a positive substitution effect). In addition, while higher levels of education may be associated with greater wealth, wealthier farmers may have more equipment to work with (which could reduce the physical effort of farming), more land to farm, and more opportunities for side businesses (all of which would lead to increased labor supply). Our results on the effects of education on employment and participation are quite robust to changes in model specification.

Other measures of income and wealth provide mixed results. We find that pension availability has no impact on men and women's labor force participation, while Giles, Wang and Cai (2011) found that rural men's pensions had a negative effect on both rural men's and women's labor force participation. We include two household-level variables as proxies for household wealth: food expenditure per capita, which is a good measure of general standard of living, and house value. House value has a small positive effect on labor force participation for both male and female elders, while food expenditure per capita has a significant negative effect for women's participation. Giles, Wang and Cai (2011) found a negative effect of house value on women's employment while Pang, deBrauw and Rozelle (2004) found no effect of per capita income on either farm or off farm employment.

While the average village-level income per capita has a significant negative effect on participation for men, the effect is small. In the annual-hours-employed model (results not shown), both men and women who live in higher-income villages report more farm hours. This means that male elders in higher income villages are less likely to identify their work status as employed, but still report higher hours of farm work. This village level income variable may be telling us more about the availability of tasks than the choice to engage in these tasks.

\section{VI.C: Health}

The results in Appendix Table A-1 reveal that age is an important determinant of labor force participation for both men and women. However, for men the decline in participation begins later, starting at age 65 to 69, while for women it begins earlier, starting at age 55 to 59 . We interpret this gender differential as evidence of the cultural or normative aspects of age on employment; women and men differ in whether they characterize their labor as employment.

In the hours of work models (results not shown) for men, off-farm hours begin to decline with the age cohort of 55 to 59, while hours of farm work do not begin to decline until the age cohort of 65 to 70 . There the drop is quite large, 227 fewer annual hours than for men age 50 to 54. For women, the decline in hours begins with the age cohort of 55 to 59 for off-farm work and at 60 to 64 age cohort for farm work. Women, age 60 to 64, report 172 fewer annual hours of farm work per year compared to those age 50 to 54 .

As expected, having a self-reported disability that affects daily living is a strong negative predictor of labor force participation for both men and women. Its effect is much larger for men. 
Women who report having had physical or psychological difficulty with tasks in the previous month also have lower labor force participation. For men the effect of this variable is smaller and more imprecisely measured. It is negative and statistically significant in the annual hours of farm work model for both men and women. Having experienced a physical or psychological difficulty with tasks in the previous month results in as large a negative effect on annual farm hours worked as does disability.

\section{VI.D: Minority Group Membership}

In the model presented in Appendix Table A-1, ethnic minority status appears in three different places; ethnic minority indicators are entered directly and are also interacted with two age categories. This strategy allows us to look at the direct effect of ethnicity on participation and its indirect effects through differences in the age trajectory of participation decline. Based on Figure 1, we include interactions of ethnicity with both the 55 to 59 and the 60 to 64 age cohorts for women and both the 60 to 64 and the 65 to 69 age cohorts for men. These intervals represent the key moments of decision making about work transitions for female and male elders, respectively.

Recall from Table 4 that there are substantial differences in the raw labor force participation rates by ethnicity and gender. However, it is possible that some of the observed differences are due to the very different demographic profiles and economic circumstances of particular ethnic groups. Members of different ethnic minority groups reside in different areas of the country, farm very different kinds of land, and are more or less likely to coreside with their adult children. The results of the multivariate analysis presented in Appendix Table A-1 reveal that substantial differences in labor force participation patterns among ethnic groups remain, even after controlling for all of the variables already discussed. While most of the differences in ethnic minority labor force participation rates appear to be due to the direct effect of ethnicity on labor force participation, we also find some significant ethnic differences in the age gradient decline in labor force participation, especially for men.

[Table 7 here]

Table 7 presents the overall effect (the sum of the direct and indirect pathways) of ethnic minority group membership on labor force participation. The numerical values presented in this table are estimated marginal effects in comparison to the Han majority. For example, all else held constant, female Mongolian elders are 17 percentage points more likely to identify themselves as being in the labor force than female Han elders. The Miao, Yao, and Tujia elder women have even higher rates of labor force participation--the Tujia women's participation rate is 27 percentage points higher than the Han's. Zhuang and Dong women's participation are also higher than the Han's by about 10 percentage points. The Hui and the Tibetans have lower rates of elder women's labor force participation than the Han. 
The overall effects of ethnic minority group membership on labor participation for men, reported in Table 7, paint a similar picture to that of the women except for the Uygurs. The Uygurs are distinct from other ethnic groups in that their female elders' labor force participation rate is lower than Han women's (but estimated imprecisely), while their men's participation rate is significantly higher than the Han's. In all, seven of the nine ethnic minority groups have labor force participation rates for male elders significantly higher than that of the Han. The Hui and the Tibetans’ rates appear to be lower than the Han’s, but are estimated imprecisely.

In most cases, the ethnic minority differentials are larger for women than men. The Tujia have the highest rates of participation for both men and women. We note that not all participation differentials translate to significant differences in annual hours worked. For men, the Hui have significantly lower annual hours worked and the Uygur, Miao, and Tujia have significantly higher annual hours worked. For women, the Hui have significantly lower hours worked and the Miao have significantly higher (results not shown). ${ }^{9}$

Most of the effect of ethnicity for women is the result of the direct effect. In terms of the indirect age interaction effects, the Hui women age 55 to 59 have significantly lower rates and the Tujia women age 55 to 59 have significantly higher rates of labor force participation than the Han women of the same age. In the 60 to 64 age range, only the Tibetans show a significantly steeper decline than the Han women. For men the age/minority interactions are more important. That the Mongolians, Hui, Uygurs, and Miao all have lower rates of labor force participation at age 60 to 64 than the Han reveals they have a much steeper age gradient the Han, given that their participation rates at younger ages were higher than those of the Han. The Uygurs and the Dong have lower rates of labor force participation at age 65 to 69 than the Han. Cultural differences, as proxied by ethnic group membership, thus, appear to affect how elders see themselves in terms of their work status. Cultural differences also affect the time interval at which they switch to regarding themselves as "keeping house."

We apply a decomposition technique to our multivariate results to determine how much of the labor force participation gap between the individual ethnic minority groups and the Han is the result of differences in their socioeconomic attributes and how much is the result of direct and indirect cultural differences. ${ }^{10}$ The results of the decomposition exercise reveal that attribute differences alone would result in a Han rate of labor force participation higher than that of the ethnic minority groups' rates for all groups for both men and women. However as noted above, most ethnic minority participation rates are, in fact, higher than the Han's. We thus find that the direct and indirect effect of ethnic minority group membership are entirely responsible for each

\footnotetext{
${ }^{9}$ These results come from multivariate models similar in specification to the one presented in Appendix Table A-1 except without age/minority interactions. Annual hours of work has more missing values than work status leading to sample sizes that are not sufficient for stability of the age-interacted model. The qualitative results reported in Table 7 remain in the LFP model estimated without age/minority interactions.

${ }^{10}$ We employ the Borooah and Iyer (2005) technique as did Maurer-Fazio, Hughes, and Zhang (2010) for analyzing differences across multiple groups. Results available from authors.
} 
of the situations where the ethnic group rates are higher than the Han's. Likewise, the direct and indirect effects of ethnic minority group membership are responsible for much of the gaps in participation between the Han and the Hui and Tibetan men and women and for Uygur women. Each of these groups has lower rates of labor force participation than the Han.

\section{VII: Discussion and Conclusion}

This paper has considered the work to "retirement" transitions of rural elders residing in the seven minority regions included in the CHES data. These regions were selected for inclusion in the survey because of their substantial minority populations. The data are ideal for examining the effect of cultural differences on a key lifecycle event, the reduction of market-oriented work with age. Membership in particular ethnic minority groups is used to proxy the potential differences in the culture of aging and caregiving. Cultural differences are also observed in the gendered differences in the effects of aging and widowhood.

Although we expected that the demand for elders' labor, as proxied by households with out-migrants, the number of out-migrants from the village, and residence in a village with a higher share of prime-age off-farm labor, would affect labor force participation rates of elders, we find that none of these variables matter in statistically significant ways. We also expected that coresidency with adult children would affect the demand for elders' labor. We find that it has a negative effect for women, but not for men. And, interestingly, coresidency does not appear to affect annual hours worked for either men or women. This leads us to conclude that for some women, coresidency changes their work -- away from market-oriented farm work towards domestic-use farm work. For men, it does not even appear to do this.

Similarly, we expected labor force participation to decline with wealth for rural elders. For men, village income is negatively related to labor force participation. For women, household food expenditure per capita is negatively related to labor force participation. Both of these effects are quite small. Education and house value affect labor force participation in the other direction; higher education and house values lead to higher rates of labor force participation for both men and women. We hypothesize the higher wealth that comes from higher education and house value leads to households having more labor saving farm equipment and more side businesses such that there are more tasks available that suit elders in that they do not require as much strength and endurance.

Beyond education, the strongest predictors of labor force participation for China's rural elders are age, disability, widowhood, and ethnic minority status. Age and disability certainly reflect health limitations, which can affect the ability to work. But age also appears to have a cultural component: the steepness of the age gradient differs between men and women and, for men especially, by ethnicity. Widowhood can also be thought of as having a cultural 
component; it seems to be part of the definition of being "too old" for market-oriented work. Widowhood reduces the probability of positive hours of farm work for women, but not men.

Finally, we find robust effects of ethnic minority group status on labor force participation. For male elders, the Han are less likely to be in the labor force than men of most of the ethnic minority groups included in this study but there are substantial differences among the ethnic groups. For female elders, the Hui and Tibetans are less likely to be in the labor force than the Han, but Mongolians, Miao, Zhuang, Dong, Yao and Tujia are more likely to be in the labor force. The difference between Tujia and Han is quite large for both men and women. Uygurs are unique among the minority groups included in the CHES in the sense that being Uygur lowers the probability of labor force participation for women and raises it for men. A decomposition analysis revealed that attribute differences predict higher rates of labor force participation for Han than for ethnic minority groups in each case. As such, each of the cases where ethnic minority group rates exceed those of the Han can be attributed solely to cultural differences.

One important lesson from this analysis, given the large differences between the Hui and Tibetans compared to the Tujia, Miao, Zhuang, Dong, Yao and Mongolians, is that differences among ethnic minority groups can be large. It is thus misleading, in the analysis of the labor force participation of rural elders, to simply dichotomize ethnic minority and majority (Han) group membership. Careful qualitative research is needed to help us understand the differences in perceptions of aging among China's rural ethnic minority groups.

Future work with the CHES data could consider other loci of decisionmaking where culture, proxied by ethnic group membership, may play a role in the key decisions of China's rural residents. It would also be interesting to explore whether similar culture differentials exist in the labor force participation patterns of China's urban elders. Other researchers report that cultural differences are maintained, though dampened, for at least one generation following migration. (Blau, et al 2013; Alesina and Giuliano, 2007)

Our results may be of value to policy makers in China concerned with issues related to migration, aging and social support. Many of the households studied here include out-migrants currently residing in cities. Although our analysis of out-migration did not reveal any significant effect on elders' work, we speculate that this may be because the household migrants are the grandchildren, rather than the children of the rural elders studied here. But as the average age of migrants increases and more migrants settle permanently in urban areas, rural elders may find themselves bearing even more of the responsibility for farming than they already do. We find that widowhood and age clearly serve as thresholds for withdrawing from market work. Policy makers need to consider what will happen when the widows and elders find themselves effectively alone in these rural villages. They also need to be conscious of the strong cultural components present in the interplay of work, living arrangements, and aging. 


\section{List of works cited}

Alesina, Alberto and Giuliano,Paola. 2007. “The Power of the Family,” NBER Working Paper 13051.

Amuss, Pamela and Stevan Harrell, editors. 1981. Other Ways of Growing Old : Anthropological Perspectives, Stanford, Calif. : Stanford University Press.

Blau, Francine, Lawrence Kahn, Albert Yung-Hsu Liu, and Kerry Papps. 2013. “The Transmission of Women's Fertility, Human Capital, and Work Orientation across Immigrant Generations,” Journal of Population Economics, 26 (2), 405-35.

Borooah, V.K. and S. Iyer. 2005. "The Decomposition of Inter-group differences in a Logit Model: Extending the Oaxaca-Blinder Approach with an Application to School Enrollment in India,” Journal of Economic and Social Measurement 30(4), 279-293.

Burda, Michael, Daniel Hamermesh, and Philippe Weil. 2013. “Total Work and Gender: Facts and Possible Explanations.” Journal of Population Economics 26 (1): 239-61.

Cai, Fang, John Giles, Philip O’Keefe, and Dewen Wang. 2012. The Elderly and Old Age Support in Rural China: Challenges and Prospects. The World Bank: Washington, D.C.

Chang, Hongqin, Xiaoyuan Dong and Fiona MacPhail. 2011. "Labor Migration and Time Use Patterns of the Left-behind Children and Elderly in Rural China,” World Development 39(12), 2199-2210.

Connelly, Rachel, Margaret Maurer-Fazio, and Dandan Zhang. 2014. "The Role of Coresidency with Adult Children in the Labor force participation Decisions of Older Men and Women in China” IZA Discussion Paper Series, IZA DP No. 8068, pp. 1-41.

Connelly, Rachel, Michael Iannotti, Margaret Maurer-Fazio, and Dandan Zhang, 2015. “Coresidency, Ethnicity, and Happiness of China’s Rural Elders,” Eurasian Geography and Economics, pp.1-19. DOI: 10.1080/15387216.2015.1058174

Gendell, Murray. 2008. "Older workers: increasing their labor force participation and hours of work,” Monthly Labor Review. January: 41-54.

Giles, John, Dewen Wang, and Wei Cai. 2011. "The Labor Supply and Retirement Behavior of China’s Older Workers and Elderly in Comparative Perspective,” Policy Research Working Paper 5853, World Bank, Development Research Group.

Maurer-Fazio, Margaret, James Hughes, and Dandan Zhang. 2007. “An Ocean Formed from One Hundred Rivers: The Effects of Ethnicity, Gender, Marriage, and Location on Labor Force Participation in Urban China, Feminist Economics 13(3-4), 159-187. 
Maurer-Fazio, Margaret, James Hughes, and Dandan Zhang. 2010. “A Comparison and Decomposition of Reform-Era Labor force participation Rates of China's Ethnic Minorities and Han Majority,” International Journal of Manpower 31(2), 138-162.

Maurer-Fazio, Margaret, Rachel Connelly, Chen Lan, and Lixin Tang. 2011.

"Childcare, Eldercare, and Labor force participation of Urban Women in China: 19822000,” Journal of Human Resources 46(2), Spring, 261-294.

Mu, Ren and Dominique van de Walle. 2011. “Left Behind to Farm? Women’s Labor Reallocation in Rural China,” Labour Economics 18, 583-597.

Pang, Lihua, Alan deBrauw, and Scott Rozelle. 2004. "Working Until You Drop: The Elderly of Rural China,” China Journal 52, 73-94.

Terza, Joseph, Anirban Basu, and Paul Rathouz. 2008. “Two-stage Residual Inclusion Estimation: Addressing Endogeneity in Health Econometric Modeling,” Journal of Health Economics 27, 531-543.

World Bank. 2014. Inclusive Urbanization and Rural-Urban Integration, Supporting Report 4. SRs4-7. 

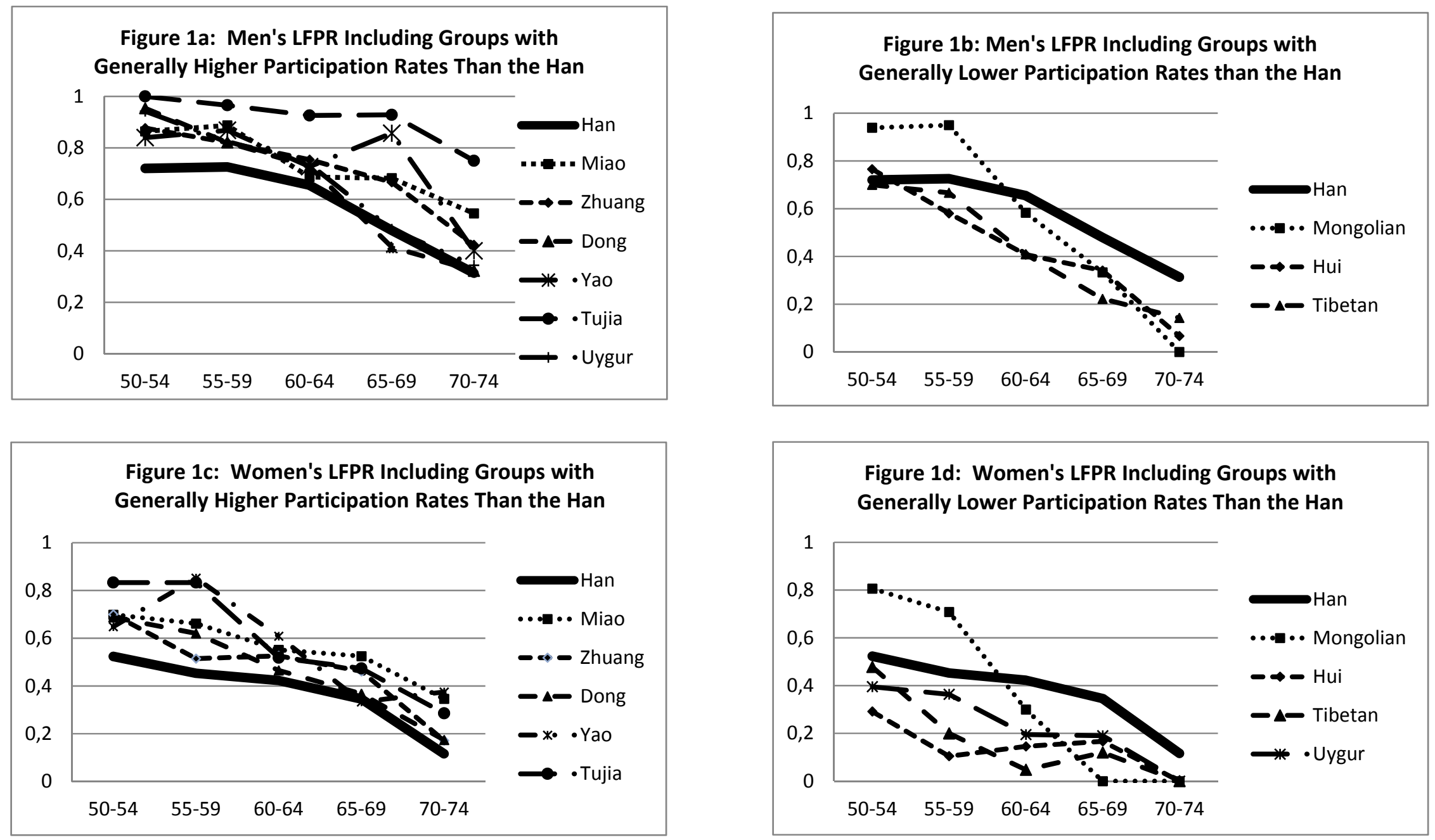
Table 1: Labor Force Participation Rate Based on Work Status During the Final Week of 2011

\begin{tabular}{|c|c|c|c|c|}
\hline & Men & Women & $\begin{array}{l}\text { Sample } \\
\text { Size } \\
\text { Men }\end{array}$ & $\begin{array}{l}\text { Sample } \\
\text { Size } \\
\text { Women }\end{array}$ \\
\hline 50 to 54 & $79.6 \%$ & $56.8 \%$ & 862 & 829 \\
\hline 55 to 59 & $76.8 \%$ & $48.2 \%$ & 1,054 & 1,022 \\
\hline 60 to 64 & $66.1 \%$ & $42.0 \%$ & 817 & 691 \\
\hline 65 to 69 & $51.6 \%$ & $34.5 \%$ & 483 & 414 \\
\hline 70 to 74 & $35.0 \%$ & $16.2 \%$ & 314 & 284 \\
\hline All elders LFPR & $67.9 \%$ & $44.6 \%$ & 3455 & 3160 \\
\hline $\begin{array}{l}\text { Unemployment } \\
\text { rate of those in } \\
\text { labor force }\end{array}$ & $4.0 \%$ & $1.7 \%$ & & \\
\hline
\end{tabular}


Table 2: Alternative Definitions of Employment

\begin{tabular}{|c|c|c|c|c|c|c|}
\hline & \multicolumn{3}{|c|}{ Men } & \multicolumn{3}{|c|}{ Women } \\
\hline & $\begin{array}{l}\text { Work } \\
\text { Status } \\
\text { Employed }\end{array}$ & $\begin{array}{l}\text { Daily } \\
\text { Hours } \\
\text { Employed }\end{array}$ & $\begin{array}{l}\text { Annual } \\
\text { Hours } \\
\text { Employed }\end{array}$ & $\begin{array}{l}\text { Work } \\
\text { Status } \\
\text { Employed }\end{array}$ & $\begin{array}{l}\text { Daily } \\
\text { Hours } \\
\text { Employed }\end{array}$ & $\begin{array}{l}\text { Annual } \\
\text { Hours } \\
\text { Employed }\end{array}$ \\
\hline $\begin{array}{l}\text { All } \\
\text { elders }\end{array}$ & & & & & & $86.4 \%$ \\
\hline 50 to 54 & $76.5 \%$ & $96.0 \%$ & $93.9 \%$ & $55.7 \%$ & $95.2 \%$ & $94.0 \%$ \\
\hline 55 to 59 & $73.9 \%$ & $96.2 \%$ & $93.9 \%$ & $48.0 \%$ & $92.4 \%$ & $92.1 \%$ \\
\hline 60 to 64 & $63.2 \%$ & $92.9 \%$ & $89.6 \%$ & $41.4 \%$ & $86.5 \%$ & $83.1 \%$ \\
\hline 65 to 69 & $49.9 \%$ & $87.8 \%$ & $84.0 \%$ & $33.3 \%$ & $78.3 \%$ & $72.1 \%$ \\
\hline 70 to 74 & $34.1 \%$ & $68.5 \%$ & $68.1 \%$ & $15.5 \%$ & $48.6 \%$ & $52.5 \%$ \\
\hline $\begin{array}{l}\text { Total } \\
\text { Sample }\end{array}$ & & & & & & \\
\hline Size & 3530 & 2739 & 3289 & 3240 & 2317 & 2852 \\
\hline
\end{tabular}


Table 3: Average Daily Hours Spent in "Work" and Housework in Rural China by Elders age 50-74

\begin{tabular}{|c|c|c|c|c|c|c|c|c|c|c|c|c|c|c|}
\hline & \multicolumn{4}{|c|}{ Work } & \multicolumn{4}{|c|}{ Housework } & \multicolumn{4}{|c|}{ Work Plus Housework } & \multicolumn{2}{|c|}{$\begin{array}{l}\text { Work Plus } \\
\text { Housework }\end{array}$} \\
\hline & \multicolumn{2}{|c|}{ Men } & \multicolumn{2}{|c|}{ Women } & \multicolumn{2}{|c|}{ Men } & \multicolumn{2}{|c|}{ Women } & \multicolumn{2}{|c|}{ Men } & \multicolumn{2}{|c|}{ Women } & & \\
\hline & $\begin{array}{l}\text { Out of } \\
\text { Labor }\end{array}$ & $\begin{array}{l}\text { In } \\
\text { Labor }\end{array}$ & $\begin{array}{l}\text { Out of } \\
\text { Labor }\end{array}$ & $\begin{array}{l}\text { In } \\
\text { Labor }\end{array}$ & $\begin{array}{l}\text { Out of } \\
\text { Labor }\end{array}$ & $\begin{array}{l}\text { In } \\
\text { Labor }\end{array}$ & $\begin{array}{l}\text { Out of } \\
\text { Labor }\end{array}$ & $\begin{array}{l}\text { In } \\
\text { Labor }\end{array}$ & $\begin{array}{l}\text { Out of } \\
\text { Labor }\end{array}$ & $\begin{array}{l}\text { In } \\
\text { Labor }\end{array}$ & $\begin{array}{l}\text { Out of } \\
\text { Labor }\end{array}$ & $\begin{array}{l}\text { In } \\
\text { Labor }\end{array}$ & & All \\
\hline & Force & Force & Force & Force & Force & Force & Force & Force & Force & Force & Force & Force & All Men & Women \\
\hline All elders & 3.6 & 6.2 & 3.4 & 6.0 & 1.7 & 1.7 & 2.9 & 3.0 & 4.7 & 7.5 & 6.0 & 8.5 & 6.6 & 7.3 \\
\hline 50 to 54 & 4.1 & 6.5 & 4.2 & 6.2 & 1.5 & 1.5 & 3.3 & 2.9 & 5.0 & 7.6 & 6.8 & 8.7 & 7.0 & 8.0 \\
\hline 55 to 59 & 4.4 & 6.4 & 4.2 & 6.1 & 2.0 & 1.6 & 3.1 & 3.0 & 5.8 & 7.6 & 6.9 & 8.6 & 7.1 & 7.8 \\
\hline 60 to 64 & 3.7 & 6.1 & 3.1 & 6.0 & 1.6 & 2.0 & 2.7 & 3.2 & 5.1 & 7.4 & 5.7 & 8.6 & 6.6 & 7.1 \\
\hline 65 to 69 & 3.1 & 6.0 & 2.3 & 5.6 & 1.7 & 1.8 & 2.6 & 2.7 & 4.1 & 7.4 & 4.5 & 7.7 & 6.1 & 6.0 \\
\hline 70 to 74 & 1.7 & 5.0 & 1.0 & 4.9 & 1.3 & 1.6 & 1.9 & 2.6 & 2.1 & 6.8 & 2.7 & 6.9 & 4.3 & 3.8 \\
\hline
\end{tabular}


Table 4: Labor Force Participation Rates of Rural Elders, Age 50 to 74

$\begin{array}{lcc}\text { Han } & \text { Men } & \text { Women } \\ \text { Mongolian } & 64.8 \% & 43.4 \% \\ \text { Hui } & 81.7 \% & 60.8 \% \\ \text { Tibetan } & 50.2 \% & 15.0 \% \\ \text { Uygur } & 47.7 \% & 20.4 \% \\ \text { Miao } & 70.8 \% & 28.7 \% \\ \text { Zhuang } & 75.5 \% & 58.3 \% \\ \text { Dong } & 77.4 \% & 52.1 \% \\ \text { Yao } & 71.1 \% & 51.0 \% \\ \text { Tujia } & 79.6 \% & 63.3 \% \\ \text { Other } & 94.3 \% & 61.8 \% \\ & 57.4 \% & 31.3 \%\end{array}$


Table 5: Educational Attainment of Elders by Gender and Ethnicity (\%)

\begin{tabular}{lcccccc}
\multicolumn{1}{c}{} & Mon & & Women & \\
& Primary & Primary & $\begin{array}{l}\text { Middle } \\
\text { School and }\end{array}$ & $\begin{array}{l}\text { No } \\
\text { Primary }\end{array}$ & $\begin{array}{c}\text { Primary } \\
\text { Siddle }\end{array}$ & $\begin{array}{l}\text { School and } \\
\text { School }\end{array}$ \\
& School & School & Above & School & School & Above \\
Han & 12.8 & 39.2 & 48.0 & 37.7 & 42.3 & 20.0 \\
Mongolian & 2.9 & 28.6 & 68.6 & 13.7 & 45.2 & 41.1 \\
Hui & 48.7 & 32.5 & 18.9 & 80.8 & 17.8 & 1.4 \\
Tibetan & 31.7 & 55.8 & 12.5 & 69.6 & 29.4 & 1.1 \\
Uygur & 12.4 & 60.3 & 27.3 & 17.1 & 67.7 & 15.3 \\
Miao & 12.9 & 49.3 & 37.8 & 49.0 & 43.0 & 8.0 \\
Zhuang & 4.9 & 33.2 & 61.9 & 27.1 & 44.6 & 28.2 \\
Dong & 10.9 & 41.4 & 47.7 & 37.8 & 46.1 & 16.1 \\
Yao & 8.2 & 53.1 & 38.8 & 32.6 & 50.5 & 16.8 \\
Tujia & 2.3 & 50.0 & 47.7 & 25.3 & 62.1 & 12.6 \\
Other & 22.8 & 39.4 & 37.8 & 60.5 & 29.5 & 10.1
\end{tabular}


Table 6: Various Characteristics of Rural Elders (Age 50-74) by Ethnicity

$\begin{array}{ll}\begin{array}{ll}\text { Average share } \\ \text { of elder }\end{array} & \begin{array}{l}\text { Average share } \\ \text { of elders who }\end{array} \\ \text { households } & \text { live with an } \\ \text { with an out- } & \text { adult child } \\ \text { migrant } & \end{array}$

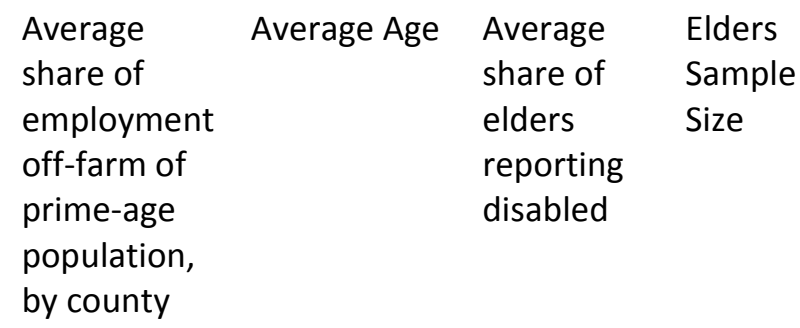

$\begin{array}{llllllr}\text { Han } & 41.4 \% & 53.4 \% & 19.1 \% & 58.8 & 3.2 \% & 2,769 \\ \text { Mongolian } & 34.5 \% & 62.9 \% & 14.1 \% & 56.7 & 2.1 \% & 145 \\ \text { Hui } & 47.6 \% & 63.4 \% & 20.4 \% & 59.9 & 4.3 \% & 443 \\ \text { Tibetan } & 27.3 \% & 88.7 \% & 22.3 \% & 60.3 & 4.4 \% & 205 \\ \text { Uygur } & 16.2 \% & 86.1 \% & 24.6 \% & 59.8 & 3.9 \% & 383 \\ \text { Miao } & 59.3 \% & 63.1 \% & 21.8 \% & 60.9 & 2.1 \% & 947 \\ \text { Zhuang } & 49.9 \% & 70.0 \% & 11.8 \% & 58.9 & 1.8 \% & 567 \\ \text { Dong } & 55.4 \% & 62.6 \% & 27.1 \% & 60.3 & 1.9 \% & 527 \\ \text { Yao } & 61.3 \% & 66.0 \% & 25.9 \% & 59.1 & 0.9 \% & 217 \\ \text { Tujia } & 52.5 \% & 58.1 \% & 17.7 \% & 60.6 & 0.6 \% & 177 \\ \text { Other } & 64.6 \% & 60.0 \% & 16.5 \% & 59.5 & 2.3 \% & 260\end{array}$


Table 7: Marginal Effects (Unconditional) of Minority Group Membership on Labor Force Participation

\begin{tabular}{lrlrl} 
& Women & & \multicolumn{1}{l}{ Men } & \\
Mongolian & 0.1728 & $* *$ & 0.1218 & $*$ \\
Hui & -0.1991 & $* * *$ & -0.0797 & \\
Tibetan & -0.1265 & $* *$ & -0.0652 & \\
Uygur & -0.0628 & & 0.1544 & $* * *$ \\
Miao & 0.2024 & $* * *$ & 0.1512 & $* * *$ \\
Zhuang & 0.1159 & $*$ & 0.1203 & $* *$ \\
Dong & 0.1146 & $* *$ & 0.0811 & $* *$ \\
Yao & 0.2263 & $* * *$ & 0.1457 & $*$ \\
Tujia & 0.2687 & $* * *$ & 0.3001 & $* * *$ \\
Other & -0.0763 & & -0.0806 &
\end{tabular}


Appendix Table A-1: Determinants of Labor Force Participation of Rural Elders

(1)

(2)

(3)

(4)

\begin{tabular}{|c|c|c|c|c|}
\hline & \multicolumn{2}{|c|}{ Women } & \multicolumn{2}{|c|}{ Men } \\
\hline & $\begin{array}{l}\text { Marginal } \\
\text { effect } \\
\text { (robust z } \\
\text { statistic) }\end{array}$ & Mean & $\begin{array}{l}\text { Marginal } \\
\text { effect } \\
\text { (robust z } \\
\text { statistic) }\end{array}$ & Mean \\
\hline $\begin{array}{l}\text { Coreside with adult } \\
\text { child }\end{array}$ & $\begin{array}{l}-0.250^{*} \\
(1.70)\end{array}$ & 0.631 & $\begin{array}{l}0.083 \\
(0.56)\end{array}$ & 0.602 \\
\hline Coresiding residual & $\begin{array}{l}0.189 \\
(1.24)\end{array}$ & -0.001 & $\begin{array}{l}-0.092 \\
(0.62)\end{array}$ & -0.003 \\
\hline Widow or widower & $\begin{array}{l}-0.100^{*} \\
(1.90)\end{array}$ & 0.147 & $\begin{array}{l}-0.157^{* * *} \\
(3.59)\end{array}$ & 0.100 \\
\hline $\begin{array}{l}\text { Household includes } \\
\text { outmigrant }\end{array}$ & $\begin{array}{l}-0.001 \\
(0.04)\end{array}$ & 0.437 & $\begin{array}{l}0.029 \\
(0.90)\end{array}$ & 0.454 \\
\hline $\begin{array}{l}\% \text { of prime age villagers } \\
\text { employed off farm }\end{array}$ & $\begin{array}{l}0.077 \\
(0.55)\end{array}$ & 0.199 & $\begin{array}{l}0.174 \\
(1.62)\end{array}$ & 0.202 \\
\hline $\begin{array}{l}\text { Number of migrants } \\
\text { From village } \\
\text { (hundreds) }\end{array}$ & $\begin{array}{l}0.006 \\
(1.40)\end{array}$ & 4.877 & $\begin{array}{l}0.008 \\
(1.41)\end{array}$ & 4.884 \\
\hline $\begin{array}{l}\text { Did not attend primary } \\
\text { school }\end{array}$ & $\begin{array}{l}-0.087^{* * *} \\
(3.01)\end{array}$ & 0.412 & $\begin{array}{l}-0.103^{* * *} \\
(3.40)\end{array}$ & 0.148 \\
\hline $\begin{array}{l}\text { Attended middle school } \\
\text { or beyond }\end{array}$ & $\begin{array}{l}0.104^{* * *} \\
(2.92)\end{array}$ & 0.164 & $\begin{array}{l}0.051^{* *} \\
(2.26)\end{array}$ & 0.425 \\
\hline Elder receives pension & $\begin{array}{l}0.040 \\
(1.11)\end{array}$ & 0.253 & $\begin{array}{l}-0.020 \\
(0.64)\end{array}$ & 0.270 \\
\hline $\begin{array}{l}\text { Food expenditure per } \\
\text { capita } \\
\text { (thousands of yuan) }\end{array}$ & $\begin{array}{l}-0.023^{*} \\
(1.66)\end{array}$ & 2.119 & $\begin{array}{l}0.021 \\
(1.56)\end{array}$ & 2.145 \\
\hline $\begin{array}{l}\text { House value } \\
\text { (thousands of yuan) }\end{array}$ & $\begin{array}{l}0.001^{* * *} \\
(3.11)\end{array}$ & 49.768 & $\begin{array}{l}0.001^{* *} \\
(2.13)\end{array}$ & 49.909 \\
\hline $\begin{array}{l}\text { Average village income } \\
\text { (thousands of yuan) }\end{array}$ & $\begin{array}{l}-0.013 \\
(1.54)\end{array}$ & 4.260 & $\begin{array}{l}-0.016^{* *} \\
(2.23)\end{array}$ & 4.243 \\
\hline Aged 55 to 59 & $\begin{array}{l}-0.074^{*} \\
(1.91)\end{array}$ & 0.315 & $\begin{array}{l}-0.030 \\
(1.07)\end{array}$ & 0.285 \\
\hline Aged 60 to 64 & $\begin{array}{l}-0.099 * * \\
(2.07)\end{array}$ & 0.215 & $\begin{array}{l}-0.044 \\
(1.03)\end{array}$ & 0.241 \\
\hline Aged 65 to 69 & $\begin{array}{l}-0.156^{* * *} \\
(3.71)\end{array}$ & 0.131 & $\begin{array}{l}-0.224^{* * *} \\
(4.43)\end{array}$ & 0.142 \\
\hline Aged 70 to 74 & $\begin{array}{l}-0.309 * * * \\
(6.27)\end{array}$ & 0.087 & $\begin{array}{l}-0.462^{* * *} \\
(9.11)\end{array}$ & 0.091 \\
\hline Disabled & $\begin{array}{l}-0.120^{*} \\
(1.70)\end{array}$ & 0.033 & $\begin{array}{l}-0.384^{* * *} \\
(4.94)\end{array}$ & 0.023 \\
\hline $\begin{array}{l}\text { Difficulty with daily } \\
\text { tasks }\end{array}$ & $\begin{array}{l}-0.115^{* *} \\
(2.26)\end{array}$ & 0.053 & $\begin{array}{l}-0.044 \\
(0.87)\end{array}$ & 0.042 \\
\hline
\end{tabular}




\begin{tabular}{|c|c|c|c|c|}
\hline Mongolian & $\begin{array}{l}0.220^{* *} \\
(2.18)\end{array}$ & 0.024 & $\begin{array}{l}0.223 * * * \\
(3.33)\end{array}$ & 0.022 \\
\hline Hui & $\begin{array}{l}-0.140 * \\
(1.94)\end{array}$ & 0.068 & $\begin{array}{l}-0.040 \\
(0.61)\end{array}$ & 0.067 \\
\hline Tibetan & $\begin{array}{l}-0.024 \\
(0.26)\end{array}$ & 0.030 & $\begin{array}{l}0.010 \\
(0.14)\end{array}$ & 0.031 \\
\hline Uygur & $\begin{array}{l}-0.076 \\
(0.86)\end{array}$ & 0.052 & $\begin{array}{l}0.208^{* * *} \\
(4.83)\end{array}$ & 0.059 \\
\hline Miao & $\begin{array}{l}0.246 * * * \\
(3.94)\end{array}$ & 0.146 & $\begin{array}{l}0.212^{* * *} \\
(4.89)\end{array}$ & 0.147 \\
\hline Zhuang & $\begin{array}{l}0.135^{*} \\
(1.67)\end{array}$ & 0.087 & $\begin{array}{l}0.131^{* *} \\
(2.29)\end{array}$ & 0.078 \\
\hline Dong & $\begin{array}{l}0.116 \\
(1.50)\end{array}$ & 0.084 & $\begin{array}{l}0.135^{* * *} \\
(2.86)\end{array}$ & 0.082 \\
\hline Yao & $\begin{array}{l}0.174 \\
(1.36)\end{array}$ & 0.030 & $\begin{array}{l}0.167^{*} \\
(1.81)\end{array}$ & 0.030 \\
\hline Tujia & $\begin{array}{l}0.227^{* *} \\
(2.03)\end{array}$ & 0.027 & $\begin{array}{l}0.268^{* * *} \\
(3.56)\end{array}$ & 0.026 \\
\hline Other minority & $\begin{array}{l}-0.173^{* *} \\
(2.12)\end{array}$ & 0.041 & $\begin{array}{l}-0.109 \\
(1.15)\end{array}$ & 0.037 \\
\hline Mongolian * 55 to 59 & $\begin{array}{l}0.130 \\
(0.82)\end{array}$ & 0.008 & & \\
\hline Hui $* 55$ to 59 & $\begin{array}{l}-0.243^{* *} \\
(2.30)\end{array}$ & 0.020 & & \\
\hline Tibetan* 55 to 59 & $\begin{array}{l}-0.151 \\
(1.19)\end{array}$ & 0.007 & & \\
\hline Uygur* 55 to 59 & $\begin{array}{l}0.099 \\
(0.93)\end{array}$ & 0.017 & & \\
\hline Miao* 55 to 59 & $\begin{array}{l}-0.005 \\
(0.07)\end{array}$ & 0.043 & & \\
\hline Zhuang* 55 to 59 & $\begin{array}{l}-0.056 \\
(0.59)\end{array}$ & 0.030 & & \\
\hline Dong * 55 to 59 & $\begin{array}{l}0.053 \\
(0.56)\end{array}$ & 0.026 & & \\
\hline Yao* 55 to 59 & $\begin{array}{l}0.282 \\
(1.42)\end{array}$ & 0.007 & & \\
\hline Tujia* 55 to 59 & $\begin{array}{l}0.374^{* * *} \\
(2.69)\end{array}$ & 0.005 & & \\
\hline $\begin{array}{l}\text { Other minority } \\
* 55 \text { to } 59\end{array}$ & $\begin{array}{l}0.005 \\
(0.04)\end{array}$ & 0.018 & & \\
\hline Mongolian * 60 to 64 & $\begin{array}{l}-0.255 \\
(1.40)\end{array}$ & 0.003 & $\begin{array}{l}-0.373^{* *} \\
(2.19)\end{array}$ & 0.004 \\
\hline Hui* 60 to 64 & $\begin{array}{l}-0.106 \\
(0.94)\end{array}$ & 0.016 & $\begin{array}{l}-0.158^{*} \\
(1.69)\end{array}$ & 0.014 \\
\hline Tibetan* 60 to 64 & $\begin{array}{l}-0.321^{*} \\
(1.85)\end{array}$ & 0.007 & $\begin{array}{l}-0.198^{*} \\
(1.83)\end{array}$ & 0.007 \\
\hline Uygur* 60 to 64 & $\begin{array}{l}-0.136 \\
(1.19)\end{array}$ & 0.013 & $\begin{array}{l}-0.169 * \\
(1.84)\end{array}$ & 0.017 \\
\hline
\end{tabular}




\begin{tabular}{|c|c|c|c|c|}
\hline Miao* 60 to 64 & $\begin{array}{l}-0.091 \\
(1.26)\end{array}$ & 0.035 & $\begin{array}{l}-0.246^{* * *} \\
(3.37)\end{array}$ & 0.035 \\
\hline Zhuang* 60 to 64 & $\begin{array}{l}0.056 \\
(0.39)\end{array}$ & 0.011 & $\begin{array}{l}-0.040 \\
(0.38)\end{array}$ & 0.018 \\
\hline Dong* 60 to 64 & $\begin{array}{l}-0.027 \\
(0.26)\end{array}$ & 0.018 & $\begin{array}{l}-0.108 \\
(1.17)\end{array}$ & 0.020 \\
\hline Yao* 60 to 64 & $\begin{array}{l}-0.013 \\
(0.07)\end{array}$ & 0.007 & $\begin{array}{l}-0.219 \\
(1.47)\end{array}$ & 0.011 \\
\hline Tujia* 60 to 64 & $\begin{array}{l}-0.096 \\
(0.68)\end{array}$ & 0.008 & $\begin{array}{l}0.003 \\
(0.01)\end{array}$ & 0.008 \\
\hline $\begin{array}{l}\text { Other minority } \\
* 60 \text { to } 64\end{array}$ & $\begin{array}{l}0.360^{* *} \\
(2.39)\end{array}$ & 0.007 & $\begin{array}{l}-0.073 \\
(0.47)\end{array}$ & 0.007 \\
\hline Mongolian * 65 to 69 & & & $\begin{array}{l}-0.410 \\
(1.40)\end{array}$ & 0.001 \\
\hline Hui* 65 to 69 & & & $\begin{array}{l}-0.019 \\
(0.20)\end{array}$ & 0.014 \\
\hline Tibetan* 65 to 69 & & & $\begin{array}{l}-0.215 \\
(1.53)\end{array}$ & 0.006 \\
\hline Uygur* 65 to 69 & & & $\begin{array}{l}-0.251^{* *} \\
(2.18)\end{array}$ & 0.008 \\
\hline Miao* 65 to 69 & & & $\begin{array}{l}-0.087 \\
(1.11)\end{array}$ & 0.027 \\
\hline Zhuang* 65 to 69 & & & $\begin{array}{l}-0.011 \\
(0.08)\end{array}$ & 0.007 \\
\hline Dong* 65 to 69 & & & $\begin{array}{l}-0.230^{* *} \\
(2.43)\end{array}$ & 0.013 \\
\hline Yao* 65 to 69 & & & $\begin{array}{l}0.109 \\
(0.61)\end{array}$ & 0.002 \\
\hline Tujia* 65 to 69 & & & $\begin{array}{l}0.073 \\
(0.38)\end{array}$ & 0.004 \\
\hline $\begin{array}{l}\text { Other minority } \\
* 65 \text { to } 69\end{array}$ & & & $\begin{array}{l}0.196^{*} \\
(1.78)\end{array}$ & 0.004 \\
\hline Observations & 2958 & & 3141 & \\
\hline
\end{tabular}

